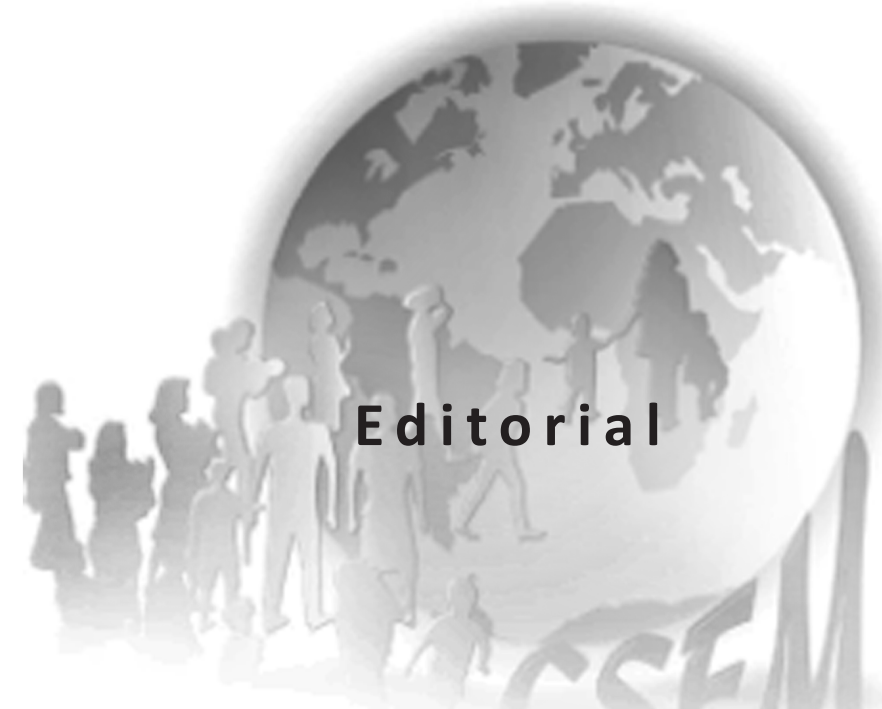

\title{
Migrações internacionais e processos comunicacionais
}

O ser humano, enquanto ser relacional, constrói a própria subjetividade a partir de processos comunicacionais, midiáticos e não midiáticos. Tais processos podem estruturar percursos de subjetivização da pessoa ou, em sentido contrário, fomentar práticas de sujeição e reificação.

As dinâmicas migratórias também estão profundamente entrelaçadas com esses processos comunicacionais, tanto no que diz respeito àqueles sujeitos que se deslocam territorialmente, quanto àqueles que se relacionam com a alteridade, com a "estrangeiridade", próxima ou distante, sincrônica ou diacrônica. No sentido amplo, comunicação e migração - enquanto "mobilidade do espírito", como diria Marc Augé - são elementos constitutivos da condição humana, intrinsecamente interconexos.

Ao tema da relação entre migrações internacionais, meios de comunicação e processos comunicacionais é dedicado o dossiê do número 46 da REMHU, Revista Interdisciplinar da Mobilidade Humana. O objetivo é visibilizar o debate atual sobre o tema, indagando até que ponto os processos comunicacionais contemporâneos constituem caminhos de promoção da dignidade do migrante ou, então, meros dispositivos de manipulação e inferiorização da alteridade.

No primeiro artigo do Dossiê, Pedro Russi desenvolve uma reflexão numa ótica epistemológica e metodológica acerca das possibilidades de estudo da relação entre processos comunicacionais - midiáticos e não midiáticos - e as dinâmicas migratórias - territoriais ou simbólicas. Sem a pretensão de esgotar a reflexão, o autor enfatiza alguns elementos desafiadores, como o papel desenvolvido pelas vivências de desterritorialização e reterritorialização dos sujeitos migrantes ou a 
função da memória nas dinâmicas de apropriação do cotidiano, nas interelações subjetivas e, de forma mais geral, na reconfiguração identitária.

A pluralização dos imaginários midiáticos sobre migrações transnacionais é um dos focos do Dossiê: as representações sociais veiculadas pelos meios de comunicação encobrem ou revelam o rosto dos migrantes? Favorecem o encontro, o diálogo, a interação ou produzem barreiras simbólicas, estereótipos?

A este propósito, Denise Cogo e Viviane Riegel desenvolvem uma atenta análise crítica do discurso de uma campanha publicitária anti-xenofobia na Inglaterra. A partir de uma fundamentação teórica focada na relação entre comunicação, cosmopolitismo e alteridade, as autoras enfatizam como a campanha visa enfrentar a xenofobia mediante a singularização das trajetórias biográficas dos migrantes. No entanto, o discurso da campanha possui uma ênfase marcadamente instrumental como se o migrante adquirisse valor apenas pela contribuição que dá -, e tende a apagar as diferenças culturais e religiosas das comunidades imigradas.

Marco Bruno, por sua vez, analisa o papel central desenvolvido pela mídia enquanto dispositivo de enquadramento que permite estruturar o discurso sobre o outro, influenciando a opinião pública e, ao mesmo tempo, estabelecendo prioridades na pauta política. Ao abordar o caso italiano, o autor destaca três tipos de fronteiras midiáticas: as coberturas dos desembarques de estrangeiros no sul da Itália; as notícias de crônica sobre atos delituosos de migrantes; a estereotipização da imigração muçulmana ("neo-racismo cultural"). Essas fronteiras midiáticas visam criar um clima de medo generalizado, que desloca a reflexão dos complexos temas da integração, da coesão social e da convivência com o outro, para a questão da segurança nacional.

O papel das mídias na construção do imaginário social em relação ao Brasil e aos brasileiros/brasileiras no exterior é o foco do artigo de Maria Badet. A autora sustenta que tal imaginário está relacionado a uma visão tropicalista, principalmente no que diz respeito à erotização da mulher brasileira. A mídia, nessa ótica, se constitui como configuradora dos imaginários sociais, mas não de forma automática, pois os processos de recepção são sempre dinâmicos e heterogêneos: "um maior conhecimento sobre as outras nacionalidades e culturas pode potencializar o deslocamento de visões de mundo reducionistas e estigmatizadas para visões mais plurais e contextualizadas das diversidades de perfis sociais que compõem uma nação e/ou cultura".

O Dossiê enfatiza também o papel positivo e propositivo desenvolvido pelas novas Tecnologias de Informação e Comunicação (TICs), frequentemente utilizadas pelos migrantes a fim de criar e fomentar redes transnacionais que podem incentivar os deslocamentos, contribuir na estruturação do projeto migratório, conservar laços interpessoais, favorecer a organização de grupos associativos e promover a integração no território. 
O artigo proposto por Cecilia Melella aborda o tema a partir da realidade dos imigrantes latino-americanos na Argentina. Conforme a autora, as TICs contribuem para que o migrante passe de uma condição de "desenraizamento" a uma condição de "conexão", com significativos efeitos tanto de um ponto de vista coletivo (rede sociais e familiares, meios de comunicação comunitários), quanto de um ponto de vista subjetivo (mitigação da sensação de solidão e saudade, preservação da identidade cultural de origem, acesso a informações sobre país de origem e destino).

Liliane Dutra Brignol e Nathália Drey Costa, por sua vez, refletem sobre práticas e processos comunicacionais relacionados com os novos fluxos migratórios para o Rio Grande do Sul, especificamente a utilização do Facebook pela diáspora senegalesa. Utilizando o conceito de webdiáspora e a metodologia da "etnografia virtual", as autoras discorrem sobre o impacto das TICs nos processos de reconfiguração e afirmação identitária, na interação com a sociedade de acolhida, na organização de redes locais e transnacionais de apoio e busca de reconhecimento.

Sobre o tema da webdiáspora versa também o artigo de Mohammed Elhajji e João Paulo Malerba. Os autores destacam as potencialidades e, ao mesmo tempo, os limites da assim chamada webradiofonia, que possibilita a preservação de laços sociais, a partilha e a manutenção de traços culturais identitários e, sobretudo, uma maior mobilização das comunidades migrantes, "tanto no plano local como transnacional, para a conquista de direitos sociais e políticos e, numa perspectiva mais ampla e mais longa, a efetivação da tão sonhada cidadania universal".

Processos comunicacionais dizem respeito também ao âmbito da educação e do sistema escolar. Marco Catarci apresenta, em seu artigo, a via italiana da interculturalidade enquanto resposta aos desafios da recente imigração. Conforme o autor, no sistema educacional italiano "a abordagem intercultural não se limita à promoção de meras estratégias de integração dos estudantes estrangeiros, mas visa o reconhecimento da diversidade como paradigma educacional, como uma oportunidade para valorizar todas as diferenças (de origem, gênero, classe social, percurso escolar)".

Por fim, Sylvia Dantas reflete sobre a utilização da tecnologia no atendimento psicológico intercultural junto a pessoas em mobilidade. A autora aborda o tema da psicoterapia online, ou seja, uma terapia realizada por e-mail, chat, mensagem instantânea, áudio ou videoconferência. A partir de pesquisas de intervenção realizadas em universidades brasileiras, a autora infere que as tecnologias constituem ferramentas importantes no processo de inserção do migrante em um novo milieu cultural, funcionando como um espaço potencial que possibilita a transição de um universo cultural a outro.

Dispositivos que permitem a promoção da cidadania ou a criação de barreiras simbólicas, que promovem o diálogo intercultural ou a demonização do outro, os meios de comunicação social e, mais em geral, os processos comunicacionais deveriam favorecer o que Marc Augé chama de "mobilidade do espírito": a 
capacidade de deslocar-se no tempo e no espaço, de sair de seu ambiente, de seu tempo, de sua 'toca cultural', para promover o encontro com outras culturas, outros povos, outras religiões. Esta é a utopia. E precisamos dela para orientar e reinventar a nossa caminhada de seres humanos.

Na seção Artigos da REMHU n. 46, Ana Vila Freyer, Eduardo Fernández Guzmán e Perla del Carpio Ovando se debruçam sobre a migração de retorno no México a partir do conceito de resiliência social transnacional, visando explorar a possibilidade de utilizar esse conceito para analisar os processos históricos de adaptação e transformação coletiva e individual no país de origem, de destino ou em contexto de circularidades. Os autores, que apresentam uma pesquisa realizada em Apaseo el Alto, Guanajuato, no México, focam o conceito de resiliência não como resignação a uma nova realidade desafiadora ou apenas como processo adaptativo, mas, principalmente, como ato de transformação biográfica em busca da plena dignidade.

Manuel Andrés Pereira reflete sobre o processo de criminalização e estigmatização de migrantes na Argentina, a partir do regime militar (1976) até 1995. Segundo o autor, o delito, a segurança e a ordem pública são os elementos que determinam a distinção entre nacionais e não-nacionais, uma distinção alicerçada, durante a ditadura, na doutrina da Segurança Nacional e, no período posterior, na retórica da violência social e da "insegurança urbana", que associa marginalidade e delinquência. Em ambos os casos constrói-se a representação da "imigração limítrofe" como ameaça para o Estado e a população autóctone, estabelecendo uma correlação direta entre "crime" e "ilegalidade migratória".

Na seção Relatos e reflexões, Giampiero Valenza reflete sobre o papel do jornalista enquanto mediador cultural, evidenciando implicações éticas e normativas referentes ao contexto italiano; já Luciano Manicardi interpreta a práxis comunicadora de Jesus de Nazaré junto aos estrangeiros em seu contexto histórico e cultural; por fim, Terezinha Lúcia Santin, Ivanir Ana Filipi e Gjeline Preçi, mscs, apresentam um precioso testemunho da práxis pastoral das Irmãs scalabrinianas na cidade de Siracusa, no sul da Itália. A seção Resenhas, Teses e Dissertações encerra o número da Revista com a apresentação da dissertação de Patrícia Nabuco Martuscelli sobre crianças soldados na Colômbia.

Desejamos a todos e todas uma boa leitura.

Roberto Marinucci (editor-chefe da REMHU) 